\title{
Surgical treatment for irreducible pediatric subaxial cervical unilateral facet dislocation: case report
}

\author{
Wei Qu, MD, Dingjun Hao, MD, Qining Wu, MD, Zongrang Song, MD, and Jijun Liu, MD \\ Department of Spine Surgery, Honghui Hospital, Xi'an Jiaotong University College of Medicine, Xi'an, China
}

\begin{abstract}
Unilateral facet dislocation at the subaxial cervical spine (C3-7) in children younger than 8 years of age is rare. The authors describe a surgical approach for irreducible subaxial cervical unilateral facet dislocation (SCUFD) at C3-4 in a 5-year-old boy and present a literature review. A dorsal unilateral approach was applied, and a biodegradable plate was used for postreduction fixation without fusion after failed conservative treatment. There was complete resolution of symptoms and restored cervical stability. Two years after surgery, the patient had recovered range of motion in C3-4. In selected cases of cervical spine injury in young children, a biodegradable plate can maintain reduction until healing occurs, obviate the need to remove an implant, and recover the motion of the injured segment.
\end{abstract}

http://thejns.org/doi/abs/10.3171/2015.10.PEDS15351

KEY WORDS pediatric cervical; subaxial unilateral facet dislocation; range of motion; nonfusion; biodegradable plate; spine

$\mathrm{S}$ UBAXIAL cervical unilateral facet dislocation (SCUFD) occurs in only 2 of every 167 cervical spine injuries (CSIs) in children younger than 8 years. ${ }^{13}$ The most common causes of pediatric subaxial CSI are motor vehicle accidents $(50 \%)$ and sports-related activities $(25 \%) .{ }^{6}$ Optimal management and treatment strategies for pediatric SCUFD remain unclear. In previous reports of pediatric SCUFD, conservative therapy and surgery were successful. , $, 6,10,14,18,21$ Most patients recovered well after management, and neurological symptoms disappeared. Only 1 patient experienced postoperative recurrence of dislocation and intervertebral instability. ${ }^{14}$ However, anterior or posterior reduction and fixation with fusion resulted in complete loss of range of motion (ROM) in the involved segments., ${ }^{5,6,14,21}$ Here, we report a surgical approach for pediatric SCUFD that preserves ROM in the dislocated segment. We treated SCUFD at C3-4 in a 5-year-old boy. At the 2-year follow-up visit there was no recurrence of dislocation or intervertebral instability, and the patient had fully recovered his preinjury quality of life.

\section{Case Report}

History and Imaging

A 5-year-old boy was hospitalized for head and neck pain and restricted cervical activity. Two days earlier he had sustained severe head and neck injuries while playing under a motor vehicle that suddenly started. Admission CT scans confirmed a left parietal-occipital bone depressed fracture and C3-4 unilateral facet fracturedislocation. The patient's head was turned slightly right in a forced position. He had normal strength and reflexes in the upper and lower extremities. Cervical radiography (Fig. 1A), 3D CT scans (Fig. 1B), and 3-T MRI sequences (Fig. 1C) showed a right-sided facet fracture-dislocation at C3-4, and no obvious disc damage.

\section{Conservative Treatment}

Because the skull fracture was accompanied by cervical dislocation, it was not treated with skull-tong traction. Instead, mandibular-occipital-bandage traction was applied, with the neck bending at $20^{\circ}$, and a trailing load of $2 \mathrm{~kg}$. After 1 week, radiographic reexamination showed that the reduction had failed. The patient underwent manual reduction under general anesthesia with somatosensory evoked potential (SSEP) and motor evoked potential (MEP) monitoring. However, there was a warning change in SSEP and MEP signals each time the reduction was nearly complete. Due to anticipated adverse outcomes, attempts at manual reduction were abandoned.

ABBREVIATIONS CSI = cervical spine injury; MEP = motor evoked potential; $R O M=$ range of motion; $S C U F D=$ subaxial cervical unilateral facet dislocation; SSEP = somatosensory evoked potential.

SUBMITTED June 9, 2015. ACCEPTED October 5, 2015.

INCLUDE WHEN CITING Published online January 1, 2016; DOI: 10.3171/2015.10.PEDS15351. 

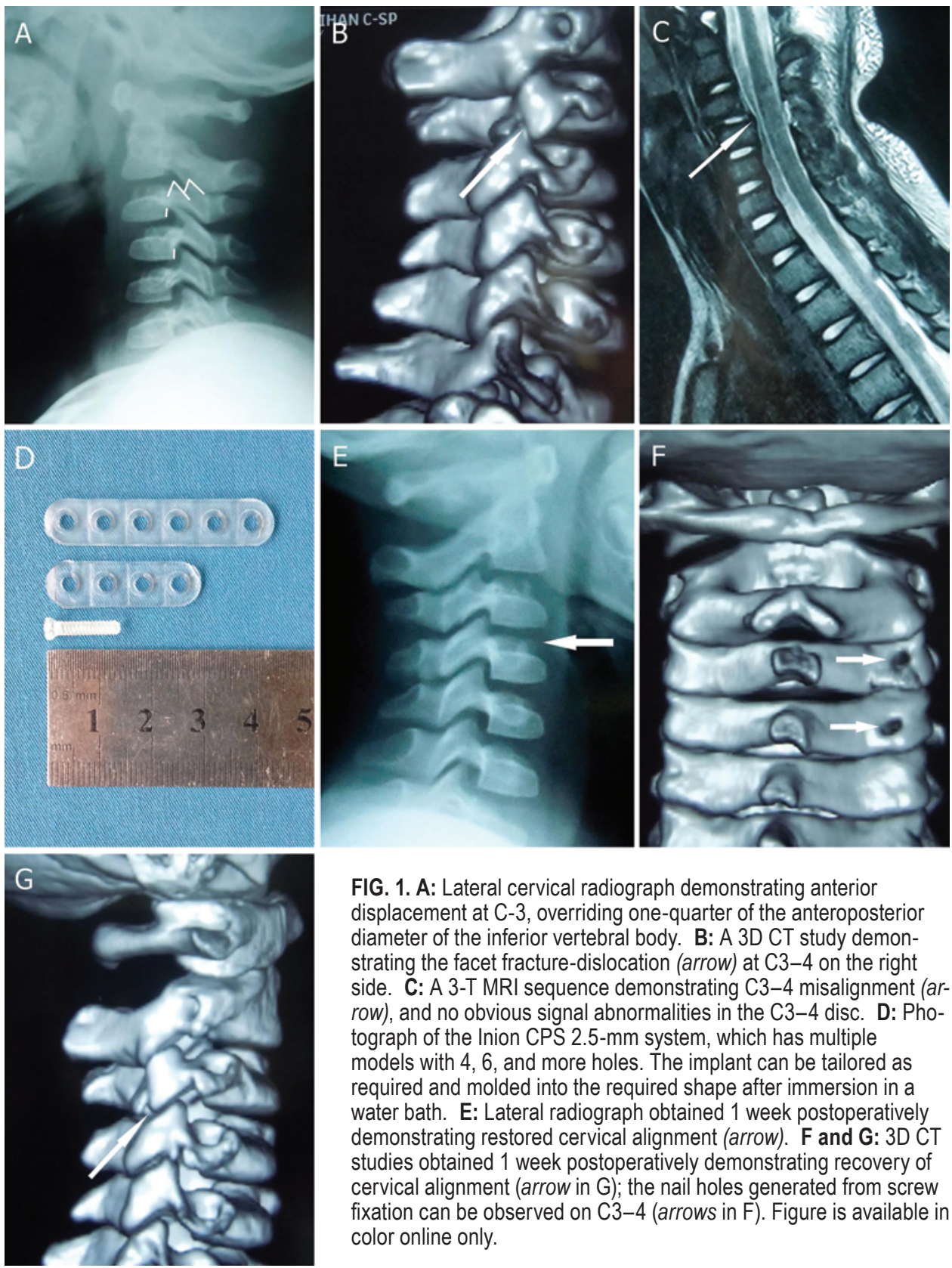

FIG. 1. A: Lateral cervical radiograph demonstrating anterior displacement at C-3, overriding one-quarter of the anteroposterior diameter of the inferior vertebral body. B: A 3D CT study demonstrating the facet fracture-dislocation (arrow) at $\mathrm{C} 3-4$ on the right side. C: A 3-T MRI sequence demonstrating C3-4 misalignment (arrow), and no obvious signal abnormalities in the C3-4 disc. D: Photograph of the Inion CPS 2.5-mm system, which has multiple models with 4, 6, and more holes. The implant can be tailored as required and molded into the required shape after immersion in a water bath. E: Lateral radiograph obtained 1 week postoperatively demonstrating restored cervical alignment (arrow). F and G: 3D CT studies obtained 1 week postoperatively demonstrating recovery of cervical alignment (arrow in $\mathrm{G}$ ); the nail holes generated from screw fixation can be observed on C3-4 (arrows in F). Figure is available in color online only.

\section{Surgical Technique}

A median posterior cervical incision was made, the C3-4 paraspinal muscle was subperiosteally stripped at the dislocation side, the lamina and lateral mass of C3-4 were exposed, and a periosteal detacher was used to poke the facet joint to reduction. This approach was a failure. A distraction pin was inserted at C-3 to distract the lateral mass while poking the C-4 lateral mass until it was restored. There was incomplete reduction of the facet joint and facet subluxation. A towel clamp was used to clamp the superior border of the C-3 lamina and the inferior border of the C-4 lamina to maintain the reduction. A $2.5-\mathrm{mm}$ biodegradable plate (Inion CPS) was chosen for immobilization (Fig. 1D). The plate was tailored and molded into the required shape after immersion in a water bath, and approximated to the lateral mass. A $1.5-\mathrm{mm}$ high-speed round bur drill was used to create an entry point $1 \mathrm{~mm}$ medial to the midline of the lateral mass. A depth-limited hand drill was applied to drill holes $15^{\circ}$ cranially and $30^{\circ}$ laterally. A bone tunnel was created. The length of the bone tunnel was continuously monitored to ensure that it did not penetrate the contralateral cortical bone. The bone tunnel was measured and an appropriate screw was selected. The bone holes were taped and the plate was fixed without a bone graft. The clamp was removed, and there was no subluxation; the plate immediately immobilized the reduction. The wound was closed in layers, and a Hemovac drain was inserted. There were no obvious warn- 

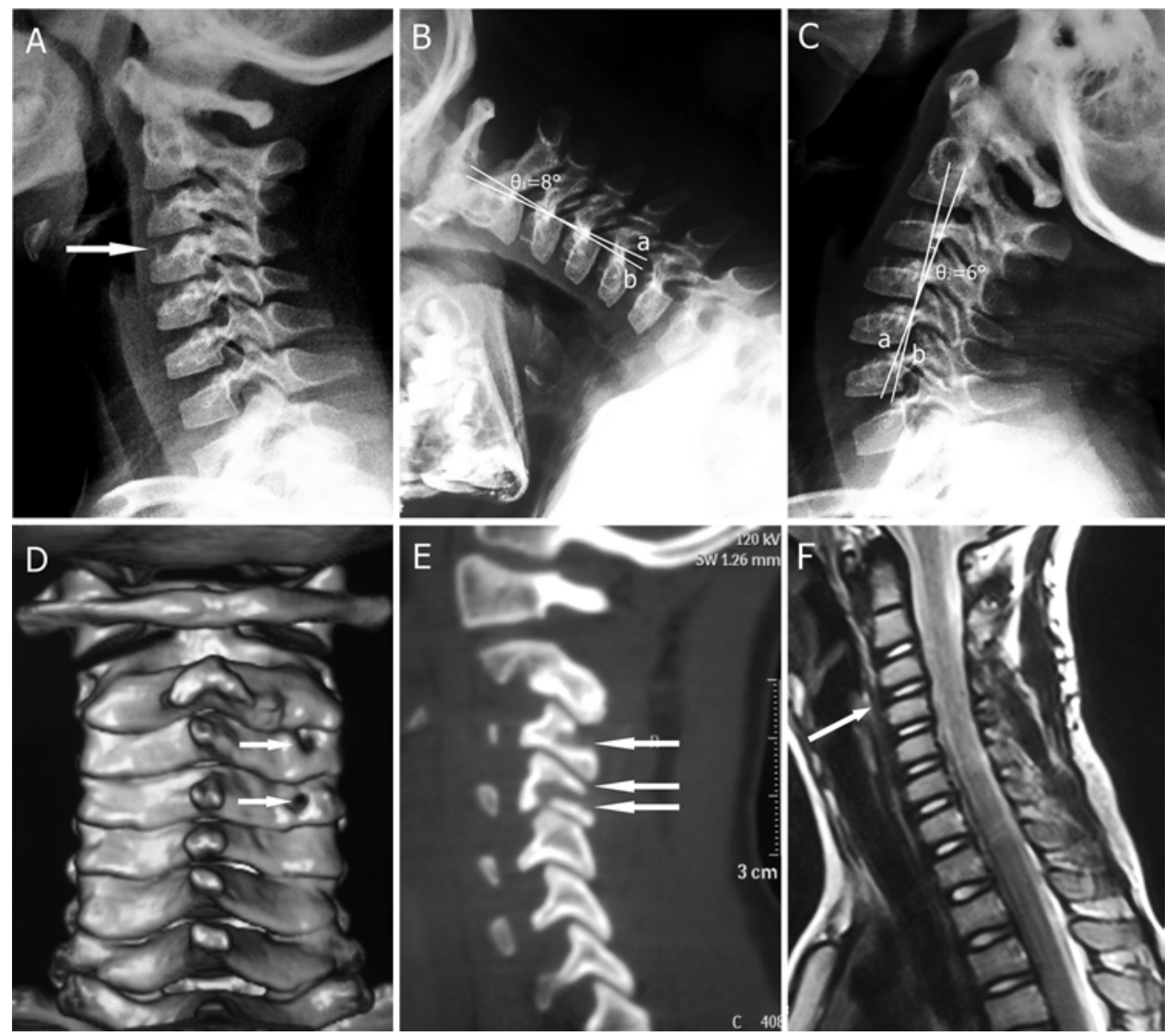

FIG. 2. A: Lateral radiograph demonstrating no recurrence of dislocation or misalignment (arrow) 2 years postoperatively. B and C: Radiographs showing good cervical alignment in flexion and extension ( $a$ is the posterior tangent of the C-3 vertebral body, $b$ is the posterior tangent of the C-4 vertebral body, and the ROM of C3-4 is the sum of $\theta_{1}$ and $\theta_{2}$, which is $14^{\circ}$ ). D and E: Follow-up CT scans obtained 2 years postoperatively demonstrating no bony fusion at the C3-4 dislocated facet joint (arrows in E). The fractured facet of $\mathrm{C}-3$ had recovered well, and the nail holes (arrows in D) were not filled with any significant bony substitution. F: A 1.5-T MRI sequence demonstrating normal signal in the C3-4 disc (arrow).

ing changes in SSEP or MEP during the operation. The patient was transferred to neurosurgery for repair of the skull fracture and was immobilized with cervicothoracic orthosis for 3 months.

\section{Postoperative Course}

Reexamination at 1 week postoperatively with radiography (Fig. 1E) and $\mathrm{CT}$ scans (Fig. $1 \mathrm{~F}$ and $\mathrm{G}$ ) revealed a normally aligned cervical vertebra. The visual analog scale for neck pain improved from a score of 8 before the operation to a score of 2 at 1 week after the operation, and a score of 0 at 2 weeks after the operation. The Neck Disability Index improved from a score of 40 before the operation to a score of 12 at 1 week after the operation, and a score of 4 at 2 weeks after the operation. Two years after the operation, radiography (Fig. 2A-C) demonstrated normal cervical alignment. The ROM in C3-4 was measured by the posterior tangent method, ${ }^{1,9}$ and the value was normal at $14^{\circ}$ (Fig. 2D and E). A follow-up 3D $\mathrm{CT}$ scan demonstrated recovery of the fractured facet at C-3, with no bony fusion at the $\mathrm{C} 3-4$ dislocated facet joint (Fig. 2F). A 1.5-T MRI sequence showed a normal signal in the $\mathrm{C} 3-4$ disc. At the 2-year follow-up visit, the patient had no neck discomfort or other complications, was able to freely participate in sports, and had fully recovered his preinjury quality of life.

\section{Discussion}

Studies on pediatric SCUFD are rare (Table 1). ${ }^{5,6,10,14,18,21}$ Although several reports focus on fusion with instrumentation, ${ }^{5,6,14,21}$ evidence suggests that cervical fusion causes complete loss of ROM in the involved segment and may lead to spontaneous fusion of adjacent joints or increase the rate of herniation on the superior disc. ${ }^{15,19}$ As a consequence, fusion should only be applied when there is no alternative. Interestingly, among the previously reported cases, only 2 (involving a 22-month-old and a 9-year-old child) $)^{5,18}$ used cervical MRI, and both patients had no obvious disc injury. This was similar to the current case; therefore, we performed unilateral fixation after reduction without fusion.

One study reported that the use of degradable suture fixation of C2-3 bilateral facet joint dislocation without fusion in a child restored ROM in C2-3 after 40 months. ${ }^{8}$ In the current case, we used a degradable plate (Inion CPS) 
TABLE 1. Summary of published reports on the management of pediatric SCUFD

\begin{tabular}{lcccccccc}
\hline Authors \& Year & $\begin{array}{c}\text { Patient } \\
\text { Age }\end{array}$ & Sex & $\begin{array}{c}\text { Injured } \\
\text { Level }\end{array}$ & $\begin{array}{c}\text { Cause of } \\
\text { Injury }\end{array}$ & Initial Examination & Clinical \\
\hline Hott et al., 2004 & 10 mos & M & C6-7 & $\begin{array}{c}\text { Fall down } \\
\text { staircase }\end{array}$ & $\begin{array}{c}\text { Neck tenderness, no } \\
\text { neurological deficit }\end{array}$ & $\begin{array}{c}\text { Stabilized w/ full-body external orthosis } \\
\text { Outcome }\end{array}$ & $\begin{array}{c}\text { Complete } \\
\text { recovery }\end{array}$ \\
\hline Sellin et al., 2014 & 7 yrs & F & C3-4 & Fall & No neurological deficit & $\begin{array}{c}\text { C2-4 posterior cervical fusion, stabilized w/ } \\
\text { lateral mass screws \& rod }\end{array}$ & $\begin{array}{c}\text { Complete } \\
\text { recovery }\end{array}$ \\
\hline Dogan et al., 2006 & 13 yrs & F & C5-6 & NR & $\begin{array}{c}\text { Incomplete neurologi- } \\
\text { cal deficit }\end{array}$ & C5-6 anterior fusion \& stabilization & Complete \\
recovery
\end{tabular}

$\mathrm{NR}=$ not reported

to immobilize the reduction. The plate kept its initial tensile strength for at least 6 weeks, and the screw maintained shear strength for $12-16$ weeks. ${ }^{17}$ Other biodegradable plates with similar attributes may also be suitable for use in pediatric SCUFD. It was also reported that the average radiological union of CSIs in a series of 188 patients (age range 15-40 years) was 11.5 weeks following immobilization with a Halo vest and satisfactory restoration of bone and ligament stability. ${ }^{4}$ In a 5-year-old patient, the healing process of injured tissues should be faster. We took a cervical radiograph 3 months postsurgery and found no dislocation. We believed that the injured tissue was healing. We removed the orthosis, and the patient began a rehabilitation program. The implant degraded 26 weeks after surgery, fragmented at 52 weeks, and was completely absorbed at 104 weeks. ${ }^{17}$ A flexion-extension cervical radiograph obtained 2 years postoperatively revealed that ROM was restored in the involved segment.

To avoid delayed cervical pain and intervertebral instability, the cervical facet should not be left in the dislocated position during healing. ${ }^{20}$ In the current case, we immobilized the reduction through internal fixation, but there was no specialized pediatric cervical internal fixation available for the patient. Because an adult-sized metallic implant for a child may create the need for an enlarged surgical incision and then for a second surgery to remove the plate, we used a biodegradable fixation after reduction. The biodegradable fixation is available in a variety of lengths and can be tailored and molded for use in pediatric patients. Biodegradable anterior cervical plates have no stress-shielding effect, do not interfere with imaging examinations, and do not need to be removed. In recent years, biodegradable plates have been increasingly applied in cervical surgery in adults. ${ }^{22}$ Evidence suggests that both biodegradable and metallic anterior cervical plates allow bone healing and have a similar intervertebral fusion rate. ${ }^{16,23}$ However, compared with metallic anterior cervical plates, the biodegradable ones have a higher failure rate after anterior fusion. ${ }^{3,12}$ In pediatric and adult mandibular fractures, the Inion CPS provides significant stability and favorable bone healing and bears the load adequate$1 y ; 2,7,11,22$ the plate is equivalent to a $2-\mathrm{mm}$ titanium plate. ${ }^{11}$ However, data describing the use of this plate in pediatric cervical surgery are limited. In the current case, outcomes in the follow-up postoperative period confirmed that our approach was satisfactory; the biodegradable plate reliably sustained the reduction until healing and allowed ROM to be fully restored in the involved segment.

\section{Conclusions}

The management of pediatric SCUFD should be individualized. In case of minimal cervical disc injury, the nonfusion technique may be a good choice. The technique involves stripping of the adjacent tissues at the dislocated side, restoration of the facet joints, and fixation with a biodegradable plate without fusion of the facet joint. In our case, this method restored the full ROM in the dislocated segment. The patient showed no obvious cervical discomfort or intervertebral instability at the 2-year follow-up visit. However, longer follow-up and more cases are required to verify this approach for the management of pediatric SCUFD.

\section{References}

1. Asazuma T, Nakamura M, Matsumoto M, Chibo K, Toyama Y: Postoperative changes of spinal curvature and range of motion in adult patients with cervical spinal cord tumors: analysis of 51 cases and review of the literature. J Spinal Disord Tech 17:178-182, 2004

2. Bali RK, Sharma P, Jindal S, Gaba S: To evaluate the efficacy of biodegradable plating system for fixation of maxillo- 
facial fractures: a prospective study. Natl J Maxillofac Surg 4:167-172, 2013

3. Brkaric M, Baker KC, Israel R, Harding T, Montgomery DM, Herkowitz HN: Early failure of bioabsorbable anterior cervical fusion plates: case report and failure analysis. J Spinal Disord Tech 20:248-254, 2007

4. Chan RC, Schweigel JF, Thompson GB: Halo-thoracic brace immobilization in 188 patients with acute cervical spine injuries. J Neurosurg 58:508-515, 1983

5. Chen Y, Wang X, Chen D, Liu X: Surgical treatment for unilateral cervical facet dislocation in a young child aged 22 months old: a case report and review of the literature. Eur Spine J 22 (Suppl 3):S439-S442, 2013

6. Dogan S, Safavi-Abbasi S, Theodore N, Horn E, Rekate HL, Sonntag VK: Pediatric subaxial cervical spine injuries: origins, management, and outcome in 51 patients. Neurosurg Focus 20(2):E1, 2006

7. Elhalawany SK, Tarakji B, Azzeghaiby S, Alzoghaibi I, Baroudi K, Nassani MZ: Clinical and radiographic evaluation of biodegradable bone plates in the treatment of mandibular body fractures. Niger Med J 56:48-53, 2015

8. Hamoud K, Abbas J: A new technique for stabilization of injuries at C2-C3 in young children. Injury 45:1791-1795, 2014

9. Harrison DE, Harrison DD, Cailliet R, Troyanovich SJ, Janik TJ, Holland B: Cobb method or Harrison posterior tangent method: which to choose for lateral cervical radiographic analysis. Spine (Phila Pa 1976) 25:2072-2078, 2000

10. Hott JS, Feiz-Erfan I, Kim LJ, Rekate HL, Sonntag VK: Nonsurgical treatment of a C6-7 unilateral locked facet joint in an infant. Case report. J Neurosurg 100 (2 Suppl Pediatrics):220-222, 2004

11. Laughlin RM, Block MS, Wilk R, Malloy RB, Kent JN: Resorbable plates for the fixation of mandibular fractures: a prospective study. J Oral Maxillofac Surg 65:89-96, 2007

12. Lebl DR, Bono CM, Metkar US, Grottkau BE, Wood KB: Bioabsorbable anterior cervical plate fixation for single-level degenerative disorders: early clinical and radiographic experience. Spine J 11:1002-1008, 2011

13. Leonard JR, Jaffe DM, Kuppermann N, Olsen CS, Leonard JC: Cervical spine injury patterns in children. Pediatrics 133:e1179-e1188, 2014

14. Maximilian F, Arndt PS, Klaus S, Christian J: Unstable cervical spinal injury in children-case report and review of the literature. Eur J Trauma Emerg Surg 34:515-521, 2008

15. McGrory BJ, Klassen RA: Arthrodesis of the cervical spine for fractures and dislocations in children and adolescents. A long-term follow-up study. J Bone Joint Surg Am 76:16061616,1994

16. Nabhan A, Ishak B, Steimer O, Zimmer A, Pitzen T, Steudel WI, et al: Comparison of bioresorbable and titanium plates in cervical spinal fusion: early radiologic and clinical results. J Spinal Disord Tech 22:155-161, 2009

17. Nieminen T, Rantala I, Hiidenheimo I, Keränen J, Kainulainen H, Wuolijoki E, et al: Degradative and mechanical properties of a novel resorbable plating system during a 3-year follow-up in vivo and in vitro. J Mater Sci Mater Med 19:1155-1163, 2008

18. Parada SA, Arrington ED, Kowalski KL, Molinari RW: Unilateral cervical facet dislocation in a 9-year-old boy. Orthopedics 33:929, 2010

19. Raizman NM, Yu WD, Jenkins MV, Wallace MT, O'Brien JR: Traumatic C4-C5 unilateral facet dislocation with posterior disc herniation above a prior anterior fusion. Am J Orthop 41:E85-E88, 2012

20. Rorabeck CH, Rock MG, Hawkins RJ, Bourne RB: Unilateral facet dislocation of the cervical spine. An analysis of the results of treatment in 26 patients. Spine (Phila Pa 1976) 12:23-27, 1987

21. Sellin JN, Shaikh K, Ryan SL, Brayton A, Fulkerson DH, Jea A: Clinical outcomes of the surgical treatment of isolated unilateral facet fractures, subluxations, and dislocations in the pediatric cervical spine: report of eight cases and review of the literature. Childs Nerv Syst 30:1233-1242, 2014

22. Singh G, Mohammad S, Chak RK, Lepcha N, Singh N, Malkunje LR: Bio-resorbable plates as effective implant in paediatric mandibular fracture. J Maxillofac Oral Surg 11:400-406, 2012

23. Tomasino A, Gebhard H, Parikh K, Wess C, Härtl R: Bioabsorbable instrumentation for single-level cervical degenerative disc disease: a radiological and clinical outcome study. $\mathbf{J}$ Neurosurg Spine 11:529-537, 2009

\section{Disclosures}

The authors report no conflict of interest concerning the materials or methods used in this study or the findings specified in this paper.

\section{Author Contributions}

Conception and design: $\mathrm{Hao}, \mathrm{Qu}, \mathrm{Wu}$. Acquisition of data: Qu, Song. Analysis and interpretation of data: Liu. Drafting the article: Qu. Critically revising the article: Hao, Wu. Reviewed submitted version of manuscript: all authors. Approved the final version of the manuscript on behalf of all authors: Hao.

\section{Correspondence}

Dingjun Hao, Department of Spine Surgery, Honghui Hospital, Xi'an Jiaotong University College of Medicine, No. 555, Friendship Rd., District Beilin, Xi' an 710054, China. email: qwqy0428@163.com. 